\title{
PANORAMA DAS DISCUSSÕES SOBRE A PAZ E A TOLERÂNCIA ${ }^{1}$
}

\author{
Luiz Paulo Rouanet \\ $P U C-S P$
}

\begin{abstract}
Resumo: $O$ presente trabalho visa tratar de duas noções correlatas, a tolerância e a paz, que se incluem no tema mais geral da justiça internacional, ou global. Entendemos por justiça internacional, ou global, não apenas o Direito Internacional, mas uma questão muita mais ampla envolvendo padrões de distribuição de riqueza, violência privada ou institucionalizada, carências de diversas ordens, como fome, falta de segurança, moradia, saúde, etc. Envolve ainda a repressão política, $o$ acesso às oportunidades em condições de igualdade e assim por diante. $O$ artigo se propõe a apresentar um panorama das discussões sobre a tolerância, desde Santo Tomás até John Rawls.

Palavras-chave: Filosofia Política, Justiça, Paz, Relações Internacionais, Tolerância.

Abstract: The present paper aims to discuss two correlate notions, tolerance and peace, which include itselves on the more general topic of international or global justice. We understand by international or global justice not only the International Right, but a far larger issue involving patterns of wealth distribution, private or institutionalized violence, many orders of needs, as starvation, lack of security, dwelling, health etc. Envolves also political reppression, the equality of opportunity and so on. This paper presents a panorama of the debate about tolerance, since St. Thomas Aquinas until John Rawls.

Key words: Political Philosophy, Justice, Peace, International Relations, Tolerance.
\end{abstract}

${ }^{1}$ Extraído de nossa tese de doutorado em Filosofia, $O$ enigma e o espelho - Uma análise dos discursos sobre a paz de Erasmo e Rawls, defendida na USP em 20/ $3 / 2000$. 
$\mathrm{U}$ $\mathrm{m}$ dos principais temas nos quais esbarramos ao pensar a aplicabilidade das medidas para se tentar diminuir a injustiça global é o da intolerância. Desde Santo Tomás, e sua Stuma contra os gentios, passando por Erasmo, com seu Lamento da paz, entre outros textos, Leibniz, com sua correspondencia, escritos em geral e atividade diplomática, Locke, e sua Carta sobre a tolerância, o Abbé de Saint-Pierre, com seu Projeto de paz perpétua na Europa, Kant, com seu $\dot{A}$ paz perpétua, ${ }^{2}$ até as discussões atuais em torno do pluralismo e do multiculturalismo muita coisa mudou. Começaremos, pois, reconstituindo os principais termos desse debate e, grosso modo, sua evolução histórica.

\section{Dois exemplos clássicos: Tomás de Aquino e John Locke}

A inserção de Santo Tomás nesse contexto se justifica, entre outras coisas, porque, na Suma contra os gentios, o doutor angélico fala a respeito da dificuldade, se não impossibilidade, de se arghmththar, ou tentar persuadir, a quem não dispõe dos mesmos referenciais. $\mathrm{O}$ trecho talvez mais conhecido dessa Suma, e também o mais central para nossa presente discussão, consiste de dois parágrafos que merecem citação na íntegra:

$\hat{E}$ dificil refutar todos os erros, e isto for duns razoues. A primeira e'stá ''m que as afirmagós sacrilegas de cata um daquele's que cairam no erro näo nos são conhecidas a tal ponto que possamos extrair delas argamentos para confundi-los. Alias, e'ra assim aute procediam os antigos doutores para destruir os erros dos paganos, aujas posigães podiam contrecer, ou porque des mesmos haziam sido pagños, on porque pelo menos vizinm e'utre os pagáos e conheciam os seus ensiname'ntos.

A segunda razão que nos impede de refutar todos os erros contrários à fé católica é que alguns dos autores desses erros, como os maometanos e os pagãos, não concordam conosco no reconhecimento da autoridade das Sagradas Escrituras, mediante as quais poderíamos convencè-los, ao passo que, com respeito aos judeus, podemos discutir à base do Antigo Testamento, e, com respeito aos cristãos heréticos, podemos discutir com base nos escritos do Novo Testamento. Assim sendo, somos obrigados a recorrer à razão natural, à qual todos necessariamente

2 Estes dois últimos tratados em nossa Dissertação de Mestrado, Rovankt, 1994 Para as demais referencias, vide a Bibliografia. 
devem aderir. Acontece, porém, que a razão natural pode enganar-se nas coisas de Deus (Aquino, 1973, pp. 64-65).

Destacamos, do primeiro parágrafo, a utilidade de se conhecer bem o adversário, quer tendo sido ele próprio um daqueles a quem se pretende refutar, quer tendo vivido entre eles. É preciso, portanto, saber como pensa o seu interlocutor, conhecer suas razões e eventual motivo do erro a fim de poder convencê-lo de algo. Independente da finalidade, a atitude de se pôr na posição do outro, querer saber como o outro pensa, é algo que merece ser retido para nossa discussão ulterior.

Do segundo parágrafo, destacamos a necessidade de um referencial comum para discussão, de uma base de informações até certo ponto compartilhada, para que se possa encetar uma discussăo visando ao convencimento das partes. No caso dos muçulmanos, tal diálogo era dificultado pela proibição, por Maomé, da leitura por "seus discípulos dos livros do Antigo e do Novo Testamento" (Ibidem, p. 70).

Para convencer, ou conterter os adversários, Tomás de Aquino propõe a utilização de duas espécies de razões, demonstrativas e prováveis:

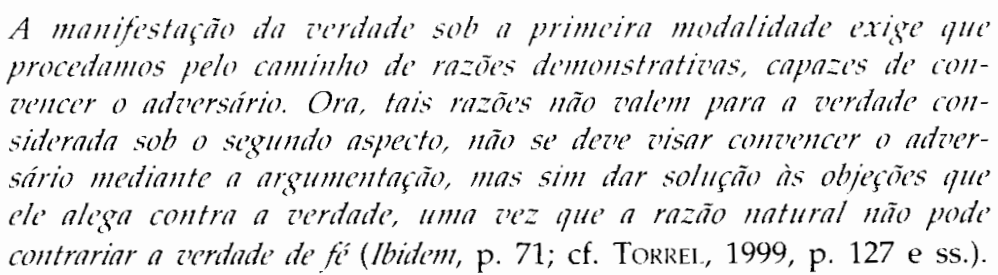

O que nos interessa aqui, e que iremos reter para nossa discussão do debate contemporâneo sobre a tolerância, é essa segunda espécie de razão, provável, que não visa argumentar ou persuadir o adversário diretamente, mas sim mediante exemplos.

Eis, portanto, o que desejamos destacar dessa brevíssima discussão do texto de Santo Tomás: sua atitude "antropológica" avant la lettre, de se posicionar no lugar do outro, a necessidade de um referencial comum e a possibilidade de uma comunicação que não vise diretamente a persuadir o adversário, buscando alternativas à razão argumentativa.

O segundo texto clássico que deve servir de base para nossa discussão é o texto de John Locke, Carta sobre a Tolerância. Na epístola - de resto muito bem escrita, desfazendo o equívoco sobre o estilo do autor, má fama devida, em parte, talvez, às traduções - o pensador inglês, solicitado a dar o seu parecer sobre as relações de tolerância entre os cristãos, revela idéias com certeza bastante avançadas para a época, embora não inéditas. Defende a completa separação entre os assuntos do governo e os assuntos religiosos. Isto visa a um duplo fim: "para que 
uns não possam camuflar sua perseguição e crueldade não cristãs com o pretexto de zelar pela comunidade e pela obediência às leis; e que outros, em nome da religião, não solicitem permissão para a sua libertinagem e licensiosidade" cia, Locke considera "acima de tudo necessário distinguir exatamente entre as funções do governo civil e da religião, e estabelecer as verdadeiras fronteiras entre Igreja e comunidade." (Ibidem).

Interessam-nos as definições que Locke dá em seguida da república (commontwealth), da sociedade civil e dos deveres do magistrado.

A republica (commonzealth) parece-me ser una sociedade de homins

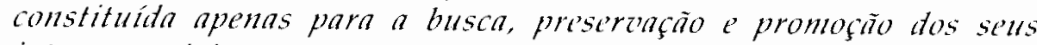
interesses cirris.

Denomino interesses civis a vida, liberdate, saide e reponso; e a posse de bens exteriores, como dinheiro, terras, moradias, mózeis e coisas que' tois.

É o deater do magristrato cioil, por meio da execugano imparial de leis

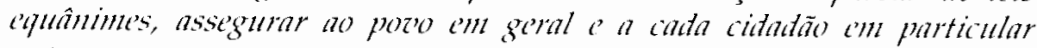
a justa posse desse's he'ns ligatos a e'sta rida (Ibidem, p. 03).

O governo civil deve, portanto, zelar pela posse dos bens terrenos. No plano religioso, porém, cada um é deixado à sua própria consciência. Ninguém, segundo Locke, pode ser obrigado a seguir um determinado credo, mesmo porque, conforme argumenta, não se pode fazê-lo sem fé, trata-se de uma convicção interior imune à coação exterior. "Toda a vitalidade e o poder da verdadeira religião consiste na persuasão íntima e plena da mente; e não existe fé sem a crença." (Ibidem). Por esse motivo, ainda, os magistrados não devem interferir em assuntos de religião, exceto quando isto de algum modo ameaçar o Estado.

Afirmo unc o poder do magistrato não se estende, pela força de suas leis, ao estabelecinento de qualauer artigo de fe, ou forma de culto. Pois as leis nẫo imperam sen penalidades, e penalidate's neste caso são absolutomente impertinentes, porque nân sĩo de molde a convencer a mente (ibitem).

Quanto à inconveniência de se ter uma religião oficial imposta pelos governantes seja em seu próprio país, seja em vários países, Locke se pronuncia da seguinte forma:

Pois se houvesse tma só verdade, uma só tia para o céll, que esperanga haveria que a maiorin dos homens a alcangasse, se os mortais fossem obrigados a ignorar os ditanes de sua própria razão e cons-

${ }^{3}$ LoCKE, 1952, p. 02, tradução nossa; para um cotejo da tradução, cf. Locke, 1978 , p. 05 .

186 Sintese, Belo Horizonte, v. 27, n. 88, 2000 


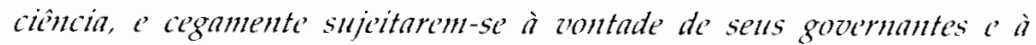
religiño alue seja a ignorincin, seja a ambição, seja a supersiticão, por azar houzesse estabeleciato nos paises onde nasceram? Na raridade $c$ contradigño de opiniôes en termos de religiño, nas quais os principes to mundo acham-se täo divididos quanto cm setus interesse's seculares, o caminho mais estrito seria o segrido; um só pais estaria certo o todo o resto do munto obrigato a seguir seus principes nas wins que lezim a destruicano; $e$ o que aumenta o absurdo, is conforma muito mal ì hogano de dizindade, os homens iriam dever sua ferlicidade on dis"graça eternas aos lugares onde nasceramt." (p. 04; p. 06).

Quanto à Igreja, Locke a define como "uma sociedade voluntária de homens que se reúnem por iniciativa própria visando à adoração pública de Deus, da maneira que julguem que Lhe seja aceitável e conducente à salvação de suas almas" (ibidem). Trata-se de uma "sociedade livre e voluntária", acrescenta.

Segue-se dessa separação entre a ordem espiritual e a material que "nenhuma pessoa privada tem direito algum de prejudicar a outra pessoa no que diz respeito a suas prerrogativas civis pelo fato de pertencer a uma outra igreja ou religião" (p. 06; p. 09).

Percebe-se indícios, no texto de Locke, de que a rigor existe até uma subordinação da Igreja ao Estado, como na seguinte passagem: "Na verdade, devemos reconhecer que a Igreja (...) tem muito mais probabilidade de ser influenciada pelo Tribunal do que este pela Igreja" (p. 10; p. 14). Cabe à república zelar pelos bens do cidadão, bens estes entendidos de modo amplo, incluindo a vida, ou mesmo a "boa vida". Só cabe ao governo intervir, como já foi dito, quanto estes bens são ameaçados por motivo de sedição. Estes motivos raramente são, diz Locke, de origem puramente religiosa.

Se os homens metem-se em conspiraçoes sediciosas, não é a religiāo

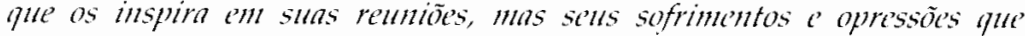
os fazem desejar libertar-se. (...) ha somente uma coisa que lern as pessoas a se romirem en roultas sediciosas, a saber, a opressiano. (p. 19; p. 25).

Locke defende o caráter saudável e necessário da diversidade de opiniōes. Diz ele: "Não foi a diversidade de opiniões (que não pode ser evitada), mas a recusa em tolerar aqueles que têm opiniões diferentes das nossas (que poderiam ter sido admitidas), que provocou todas as confusões e guerras que assolaram o mundo cristão em nome da religião" (p. 20; p. 27).

Em adendo, John Locke vai definir heréticos e cismáticos. Não pode ser herético alguém que pertence simplesmente a uma outra religião. Tanto a heresia como o cisma são ambos fracçōes dentro da mesma religião. 
Vemos assim que muitas das idéias de Locke continuam válidas e podem perfeitamente ser aproveitadas no âmbito do debate atual sobre a tolerância, que é o nosso próximo item.

\section{O debate atual sobre a tolerância: o caso Michael Walzer}

Michael Walzer é um autor normalmente considerado comunitarista e tido por alguns como "relativista". Em primeiro lugar, no debate entre "liberais e comunitaristas", Walzer parece situar-se em uma posição intermediária, mais próximo, é verdade, dos segundos do que dos primeiros, mas não totalmente identificado com aqueles. Enquanto rótulo, portanto, a denominação "comunitarista" parece explicar mal sua posição, sendo preferível uma exposição do seu pensamento em seus detalhes, com sua noção de "igualdade complexa", entre outras, o que não iremos fazer aqui ${ }^{+}$. Iremos nos centrar em sua obra sobre a tolerância e em outros textos seus que tratam direta ou indiretamente da justiça global. Em relação à acusação de "relativismo", também lidaremos com ela a seu tempo, ao respondermos às críticas que são feitas a Walzer.

Comecemos pela descrição, por Walzer, do tema de seu livro: "O meu tema é a tolerância - ou, talvez, melhor dizendo, a pacífica coexistência de grupos de pessoas com diferentes histórias, culturas e identidades, que é o que a tolerância torna possível" (WALZER, 1997, p. 02).

O que Walzer se propõe, mais do que prescrever normas de comportamento, seja por parte do Estado, seja por parte dos povos ou pessoas, normas que seriam compatíveis com uma maior tolerância global, é descrever diversas modalidades de tolerância, em um método que parece ser sua marca registrada desde os seus primeiros livros, como Das obrigações políticas, Guerras Justas e Injustas, passando por Esferas da justiça até chegar à obra que estamos analisando. O método consiste em oferecer o maior número possível de exemplos para ilustrar um determinado tema. Lembra a segunda estratégia preconizada por Tomás de Aquino, que consistia em raciocinar mediante o uso de "razões prováveis", de preferência à razão demonstrativa, ou argumentativa. Assim, Michael Walzer não está tentando persuadir o seu leitor: limita-se a apresentar o maior número de casos para que o leitor possa se convencer a si mesmo. Não se trata de um discurso "objetivista", com propo-

${ }^{4}$ Para uma visão geral do debate, cf. Stephen Mulhall \& Adam Swift (eds.), 1997. Sobre Michael Walzer, mas especificamente sobre a teoria da justiça, cf. Cap. 4, pp. 127-156. Pode-se consultar também C. Kunhathas e P. Pettit, 1995. 
sições do tipo: "A tolerância é...", ou "o comportamento tolerante consiste em...". Em vez disso, o autor procura levantar um certo número de hipóteses e explorá-las mediante o uso de exemplos 5 .

O pensamento de Michael Walzer assume que vivemos em uma sociedade pluralista, na qual dificilmente as pessoas chegarão a um consenso sobre qual $a$ melhor alternativa para uma sociedade justa. Há prós e contras em relação a todas as teorias, e consistiria em "mau utopianismo" considerar que poderia haver uma alternativa que não tivesse efeitos colaterais.
Às vezes, pelo menos, e provavelmente com muita frequiencia, as coisas que admiramos em um arranjo histórico particular acham-se funcionalmente relacionadas ìs coisas que tememos ou de que não gostamos. É um exemplo do que poderia ser chamado de "mau utopianismo" inaginar que podemos reproduzir ou imitar as primei- ras e evitar as ultimas. A filosofia tem de ser historicanchte informata $e^{\prime}$ sociologicamente competente se auiser evitar o mau utopianismo e reconthecer as duras escollas que muitas wezes precisan ser feitas no vida politica (WALZER, 1997, p. 5).

Trata-se, sem dúvida, de uma escolha "pragmática". Não discutiremos aqui as implicações filosóficas do termo, ou a corrente que dele recebe sua denominação, bastando indicar que Rorty é um dos principais herdeiros da escola que se denomina "pragmatista", e Walzer, com certeza, tem muitas afinidades com o pensamento desse autor. O que é importante esclarecer, no contexto da citação acima, é que, se Michael Walzer não se alinha simplesmente do lado dos utopistas, já que não consegue conceber um único modelo que resolva de uma vez por todas os problemas da desigualdade, da violência, da injustiça, etc., também não pode ser situado do lado dos realistas, que vêem as relações entre as pessoas e entre os povos, ou Estados, exclusivamente em termos de relações de poder, sem margem para qualquer idealismo. O que Walzer parece preconizar são modelos formados à base de tentativa e erro, apoiados na história, e submetidos ao escrutínio e aprovação dos povos envolvidos. Na continuação do parágrafo acima citado, ele diz:

\begin{abstract}
Quanto mais duras as escollas, menos provicuel é aue um resultado, ' somente um, receba aprowagão filosófica. Tale'z deramos escolher este caminho aqui e aquele outro ali, este modo agora, aquele outro no futuro. Taluez nossas escolhas devam ser tentations e experimentais, sempre sujeitas a revisão ou mesmo rejeicano (loc. cit.).
\end{abstract}

Walzer admite que sua posição é relativista, mas acrescenta que não está defendendo um "relativismo irrestrito", pois é preciso, afinal, fazer

\footnotetext{
${ }^{5}$ Em relação ao objetivismo da linguagem, cf. RICHARD RoRTY, 1992; p. ex., p. 104 e ss., Cf. também Isaiah Berlin, 1991, pp. 69-83.
} 
uma escolha, e uma escolha moral (loc. cit.). Dado o conjunto do pensamento de Walzer, podemos inferir que o seu uso do termo moral toma por referência a moral comum, aquela disseminada nas crenças e hábitos das pessoas nas sociedades de todo o mundo. Não parece provável que esteja se referindo a uma moral transcendental, do tipo kantiana, a priori.

Nesse contexto, merece citação o seguinte trecho de Rorty (1992, p. 121): "Uma ética universalista parece ser incompatível com o ironismo muito simplesmente porque é difícil imaginar afirmar tal ética sem uma doutrina sobre a natureza do homem. Tal recurso à essência real é a antítese do ironismo." Sobre Rorty e o que ele chama de "ironismo", voltaremos a falar adiante.

Quanto ao relativismo, parece difícil sequer pensar a noção de tolerância sem admitir um relativismo qualquer, mesmo que não absoluto (e "relativismo absoluto" não poderia ser mesmo considerado como uma contradição em termos? A posição dos que defendem um relativismo desse tipo parece, no limite, inconsistente) $)^{5}$.

Tomemos como exemplo de definição do relativismo - termo que, aliás, em nossa opinião, deveria ter retirada sua conotação pejorativa a priori — a de Sir Isaiah Berlin (1991, p. 76):

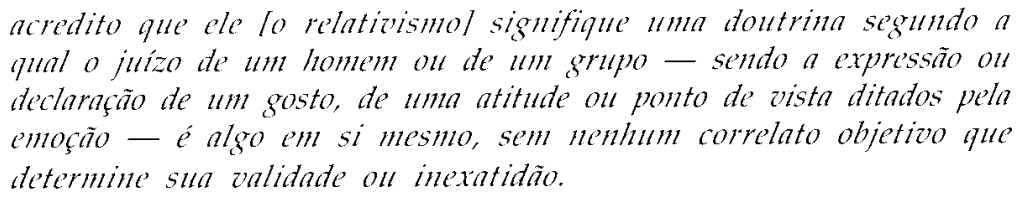

Trata-se, fundamentalmente, de uma atitude de suspensão de juizo. O que não impede de termos as nossas próprias posições, e procurarmos pô-las em debate. O que nos parece difícil de sustentar é a imposição de nossas idéias, sem alguma espécie de negociação, de busca de alternativas e da tentativa de se chegar a um acordo (embora não consenso, pois a unanimidade que esta noção implica não se revela algo factível no mundo complexo e globalizado em que vivemos).

Voltando a Michael Walzer, eis o tipo de tolerância que ele procura analisar em seu livro:

Ocupo-me, portanto, com a tolerancia quando as diferenças em jogo são culturais, religiosas, e concernentes aos modos de vida - quando os outros não são co-participantes, quando não existe jogo comum $e$

${ }^{6}$ Sobre a inconsistência dessa forma de relativismo, cf. p. ex., ERIC WeIL, 1990, p. 21 e passim. 
quando näo há uma necessidade intrinseca para as diferenças que eles cultizam e produzem (WALZER, 1997, p. 9) ${ }^{7}$.

Walzer não está preocupado em estudar a intolerância em relação a excentricidades individuais, que não constituem, a seu ver, um risco maior, nem com a intolerância propriamente política, pois, a seu ver, "a tolerância da diferença (...) é intrínseca à política democrática" (ibidem). Preocupa-se com a diferença enquanto se manifesta no dia-a-dia das comunidades, ou povos, no embate cotidiano dos grupos culturais, étnicos, religiosos etc. Esse parece ser o verdadeiro teste da tolerância, teste pelo qual seriam reprovados, atualmente, muitos países.

Em todo caso, a escolha por Walzer de esferas não diretamente políticas não é casual. Trata-se sem dúvida de uma nova visão de mundo, que procura, baseado, entre outras disciplinas, na etnografia, estudar os casos concretos tal como se manifestam no cotidiano, levando em conta as crenças, costumes locais, história dos povos a fim de entender suas especificidades, suas diferenças. Isto não significa simplesmente aceitálas, mas se trata de compreendê-las a fim de enriquecer o debate. Consentânea com essa visão de mundo é a descrição que efetua Rorty das principais diferenças entre o metafísico liberal e o (a) ironista liberal:

\footnotetext{
A associaģão que o metafísico faz da teoria à esperança social e da literatura ì perfoição prionda é invertida numa cultura liberal ironista. Dentro de uma cultura metafísica liberal, as disciplinas que cram encarregadas de penetrar para alén das muitas aparências privadas, no sentido da realidade comum geral ínica - a teologia, a ciencia, a filosofia - eram aquelas que se esperava unissem os seres humanos c, assim, ajudassem a eliminar a crueldade. Numa cultura ironista, pelo contrário, é às disciplinas que se especializavam na descrição densa to prizado $e$ do idiossincrático que se atribui essa função. Em particular, os romances $e$ as obras etnográficas, que sensibilizam para a dor dos que não falam a nossa linguagem, têm de desempentur a função que se pretendia que as demonstraçós de uma natureza humana comum desempenhassem. A solidariedade tom de ser construida a partir de pequenas peças, e não encontrada já à nossa espera, na forma de una ur-linguagem que todos reconhesamos ao ouvi-la. (RORTY, 1992, p. 128; negrito nosso).
}

Como exemplo dessa sensibilização pela literatura podemos tomar como exemplo, mais uma vez, a Isaiah Berlin que, numa espécie de autobiografia intelectual, descreve o seu contato com os escritores russos,

\footnotetext{
7 Para possibilitar um melhor acompanhamento reproduzo o texto original: "My concern, then, is with toleration when the differences at issue are cultural, religious, and way-of-life differences - when the others are not fellow participants and when there is no common game and no intrinsic need for the differences they cultivate and enact".
} 
particularmente Tolstoi, como tendo lhe revelado muito mais, talvez, sobre os aspectos morais do homem do que qualquer obra teórica:

Li Guerra e Paz, de Tolstoi, cedo demais, quando ainda era jovem. O verdadeiro impacto que me causou esse grande romance só se revelou mais tarde, junto com aquele provocado por outros escritores russos, tanto romancistas quanto pensadores sociais, da metade do século XIX. (..) A abordagem deles pareceu-me essencialmente moral: preocupavam-se de maneira mais profunda com tudo aquilo que causava injustiça, opressão e falsidade nas relaçoes huthanas, com o aprisionamento seja por muros de pedra seja pelo conformismo - a submissão aquiescente aos jugos criados pelo homem -, com a cegueira moral, o egoismo, a crueldade, o desespero, por parte de tantos homens (BerLin, 1991, pp. 14-15).

Assim, Michael Walzer parece à vontade nessa tradição de pensadores "ironistas", isto é, aqueles que duvidam de si mesmos, que não consideram que suas opiniões são absolutamente verdadeiras, a ponto de impô-las aos outros custe o que custar. Não significa que não tenham opiniões, mas buscam disseminar o que pensam por outros meios que não o discurso do conzencimento direto, da persuasão, a via argumentativa a que acima nos referimos.

No capítulo 2, Michael Walzer descreve cinco regimes de tolerância: os impérios multinacionais, a sociedade internacional, as "consociações" (federaçōes), os Estados-nações e as sociedades imigrantes. Cada um desses "tipos" representa um modelo diferente de tolerância. O primeiro, o império multinacional, consiste na "tolerância" praticada por potências conquistadoras, como foram os impérios romano e persa, por exemplo. No caso de Roma, é conhecido seu sistema de não interferir basicamente nos costumes locais, apenas assegurando a obediência de suas principais lideranças (ou exterminando-as quando não obtivesse êxito). Trata-se de uma "guetização", um reconhecimento e respeito às diferenças, dentro de certos limites. Não se trata, com certeza, de um modo "liberal ou democrático", "pode ser brutalmente repressivo com a finalidade de manter suas conquistas" (WALZFR, 1997, p. 15).

O segundo tipo de regime de tolerância é a sociedade internacional, que Walzer considera como algo bastante abstrato, já que dificilmente se trata de um regime, ou se é um, é extremamente fraco (WALZER, 1997, p. 19). Walzer diz em conclusão sobre a sociedade internacional que ela é "tolerante por princípio, e eventualmente mais tolerante, além de seus próprios princípios, devido à debilidade de seu regime" (p. 22). Em outros termos, a sociedade internacional é tolerante porque não pode ser de outra forma, devido à própria debilidade de sua estrutura, que dificilmente tem poder coativo sobre as diversas nações que a compõem. 
O terceiro tipo é o das "consociações", ou federações. Walzer tem em mente Estados bi ou trinacionais, como a Suiça, a Bélgica, o Libano ou mesmo a Bósnia (ibit.). O autor não quer excluir esse modelo, mas a tolerância parece se equilibrar aí sobre uma base frágil. Os exemplos escolhidos pelo autor demonstram a que ponto é frágil ou mesmo ausente a tolerância em regimes confederativos como os citados. Mesmo na modelar Suiça, não há como negar um tratamento diferenciado para os cantões italiano e romanche, em relação aos dominantes franceses e alemães, sendo os habitantes daqueles objetos de discriminação por parte dos habitantes destes.

O Estado-nação parece ser um lugar menos favorável à tolerância do que os tipos anteriormente citados. "Há menos espaço para a diferença nos Estados-nações, mesmo nos Estados-naçōes liberais, do que nos impérios ou consociações multinacionais - bem menos, é óbvio, do que na sociedade internacional" (p. 27).

Finalmente, o quinto regime de tolerância descrito por Walzer é o das sociedades imigrantes. Seriam sociedades que foram formadas por ondas de imigrantes, os quais têm de conviver, quer queiram, quer não, não podendo formar um Estado-nação novo exclusivamente com sua própria etnia, ou formação religiosa ou cultural. Exemplos típicos são os Estados Unidos e o Canadá, com exceção do Quebec, que se formou como uma colônia. A questäo da tolerância surge em meio à própria intolerância: cada grupo se pretende mais nativo do que o outro, mas em última instância são forçados a aceitar a presença dos demais grupos. Já se mostrou como cada grupo que chega vê a vinda de outros grupos com hostilidade, considerando-se a si próprios como habitantes mais "legítimos" do que os recém-chegados (cf. EOYANG, 1995). Já no Canadá, o princípio da tolerância já parece estar implícito em sua própria carta. Quando se assume a nacionalidade canadense, um dos principais juramentos é o de respeitar o seu próximo (Cf. GLENDON, 1991; NiCKEL, 1987; SHUE, 1996).

Nos capítulos seguintes, Walzer expõe casos complexos, nos quais nenhum desses tipos aparece de forma pura, como é o caso da França, exemplo clássico de Estado-nação e ao mesmo tempo uma sociedade imigrante (e hoje, ainda, fazendo parte da Comunidade Européia). A própria Comunidade Européia aparece para Walzer como experimento relativamente novo, e por isso difícil de ser avaliado, mas em princípio propício ao exercício da tolerância (o que não impede, ou mesmo provoca, atritos com grupos minoritários nacionais intolerantes, dentro e fora da França). Walzer examina ainda o que chama de "tolerância moderna e pós-moderna", e termina refletindo sobre o multiculturalismo nos Estados Unidos. 
Como crítica, aqui, ressentimo-nos, às vezes, de uma posição mais taxativa por parte de Walzer. Suas descrições acabam perdendo um pouco de sua validade na medida em que não vêm acompanhadas de uma reflexão mais posicionada por parte do autor. Esse método faz pensar naquele adotado por Foucault em seus livros, como Vigiar $e$ Punir, onde critica todos os sistema vigentes de punição e de educação, mas sem propor algo em seu lugar, indo de encontro ao método científico preconizado, entre outros, por Popper (1996). Não se pode rejeitar uma teoria sem outra para pôr em seu lugar. Fica aqui a observação, cujo desenvolvimento fugiria ao escopo deste artigo.

De qualquer modo, os livros de Walzer, incluindo este sobre a tolerância, que estamos examinando, procuram redescrever o mundo e, com isso, apontar para uma nova visão de mundo, alcançando o objetivo que, segundo $S$. Tomás, não poderia ser alcançado diretamente pela via argumentativa.

Para terminar este panorama, gostaria de discutir algumas idéias contidas no livro de Held, Democracia e a ordem global (HELD, 1995).

\section{O cosmopolitismo de David Held}

O livro de David Held fornece um excelente panorama do desenvolvimento dos Estados-nações, da noção de democracia, e faz uma defesa, por fim, de uma ordem global. Considera que o conceito de Estados-nações tende a desaparecer, pois cada vez menos os Estados podem se desenvolver de maneira isolada, aplicar políticas unicamente locais e tratar seus povos como se fossem sua propriedade. A própria ordem econômica mundial não permite que se adote medidas isoladas, como se não dependessem do fluxo econômico mundial.

As seguintes citações apóiam essa avaliação:

A fuga do capital para o exterior, por exemplo, é uma ameaģa constante a governos elcitos com fortes programas de reformas sociais ( $\mathrm{p}$. 13).

(...) a grobalização pode ser concebida como "ação à distância" (GidDEns, 1990). A forma particular de ação à distância que está ent questão aqui é engendrada pela acentuação $e$ aprofundamento das relaçós interfronteiriças entre os Estados-naçós e numa intensidade cada vez maior (pp. 20-21). 
A tese geral de Held é a de que cada vez mais os Estados se encontram em situação de dependência uns em relação aos outros. Evidentemente, alguns mais do que outros, como se tem visto nas crises das bolsas, que se iniciaram na Ásia e chegaram finalmente ao Brasil. Held critica também a noção de "autonomia". O ideal da autonomia deve ser deixado de lado, a seu ver, por constituir um ideal inalcançável, uma utopia, em favor da diminuição da "não-autonomia" ("Nautonomy"), que consiste nas condições que entravam o desenvolvimento ou a conquista da igualdade por parte de povos e Estados (HELI), 1995, p. 167 e ss.; para o princípio de autonomia, cf. p. 145 e ss.). "Nãoautonomia", segundo Held, "refere-se à assimétrica produção $c$ distribuiçâo de chance's-de-t'ida (life-chances) que limitam e corroem as possibilidades de participaçấo politica" (p. 171, grifos do autor). Para enfrentar tal situação, Held propõe focalizar nos "sites of poz"er", que são os seguintes: o corpo, o bem-estar (Welfare), a cultura, as associações cívicas, a economia, as relações coercivas e a violência organizada e as instituições legais e regulatórias ( $p p$. 192-194). Trata-se de defender os direitos humanos nessas áreas específicas de direitos. Amplia-se sobremaneira, dessa forma, o domínio do político, entendido não mais como o campo da política partidária e ideológica, mas como dizendo respeito às comunidades humanas como um todo.

Outro ponto a se destacar é a defesa, mais enfática do que a dos outros autores citados, da noção de democracia como a melhor forma de governo. Tal conseqüência pode ser extraída da obra dos demais autores, incluindo Walzer para quem, como vimos, a democracia é intrinsecamente tolerante (WAIZER, 1997, p. 9), com a importante ressalva de que a falta de democracia não pode servir de pretexto para o desrespeito em relação a outros países. Held faz portanto uma defesa ativa da democracia, debatendo, entre outros autores, com Robert Dahl (cf. p. ex., HEI.J, 1995, p. 169, n. 6; D^HI, 1989). Não podemos entrar nessa discussão aqui.

\section{Conclusão}

O que se pode extrair desse panorama, não exaustivo por definição, é que se caminha para uma nova visão de mundo a partir de uma efetiva reorganização do mundo. Parecem ser pontos comuns aos autores estudados a defesa da tolerância, do pluralismo e do multiculturalismo (resguardadas as diferenças de ênfase), a ampliação da noção de político, senão sua superação, em favor de um conhecimento mais abrangente, envolvendo aspectos religiosos, culturais, corporais e ou- 
tros, e a necessidade da complementação das grandes sínteses teóricas mediante o estudo de casos presentes e passados. Trata-se ainda de utilizar as diversas disciplinas (Antropologia, Economia, Filosofia, Sociologia, Psicologia, etc.) de forma integrada, a fim de se obter uma visão mais aproximada do homem (e da mulher) tal como vive em suas condições reais de existência. Não que acreditemos ser possível obter $a$ visão "verdadeira" do ser humano, o que seria expressão de um empirismo e um positivismo extremados, cada vez mais desmentidos pelos fatos (tomados em sentido amplo). Na verdade, a crença de que é possível alcançar uma compreensão verdadeira e plena do homem contribuiu para muitos dos mal-entendidos e tragédias do século $X X$, na tentativa de se organizar uma sociedade com molde nessa compreensão. Por isso, a sociedade justa, ou mais justa, só pode ser uma meta, ou ainda, para falar como Held, só podemos almejar a uma diminuiçấo das injustiças nas diversas esferas, mas não à sua efetiva eliminação, mesmo porque, como mostrava Freud, em O Mal Estar na Cultura, o homem é composto de Tântatos e Eros, morte e vida, destruição e amor, e seria ingênuo pensar que possa haver uma sociedade composta somente de Eros, embora a experiência nazista tenha mostrado que possa haver uma mais próxima de Tanatos.

Assim, desde as concepções Santo Tomás de Aquino e de Locke, passando pelas de Kant (e Hegel, não analisado), aproximamo-nos das concepções de "igualdade complexa" de Walzer e da concepção "ironista" de Rorty e, por extensão, de Berlin, sem excluir a tentativa contratualista, presente nos escritos de John Rawls e Thomas Scanlon (ainda que atenuada nos últimos escritos de Rawls) ${ }^{8}$. A esse respeito, o que alguns consideram como um maior conservadorismo de Rawls, vemos como uma compreensão, da parte de Rawls, de que a sociedade menos injusta só poderá ser alcançada, ou aproximada, por meio do consenso, e portanto da tolerância.

Rawls, 1971, 1996; SCANLON, 1992, in SEN and Williams, 1992. 


\section{Bibliografia}

Aquino, Tomás de. Súmula contra os gentios [preâmbulo]. Trad. Luiz João Baraúna. In Os Pensadores, São Paulo: Abril Cultural, 1973.

BerLIN, Isaiah. Os limites da utopia. Trad. Valter Lellis Siqueira. São Paulo: Companhia das Letras, 1991, pp. 69-83.

DAHL, Robert. Um prefácio à teoria democrática. Trad. Ruy Jungmann. Rio de Janeiro: Jorge Zahar, 1989.

1997. Poliarquia. Trad. Celso Mauro Paciornik. São Paulo: Edusp,

Eorang, Eugene. Coat of Many Colors. Boston: Beacon Press, 1995.

Giddens, Anthony. The Consequences of Modernity. Cambridge: Polity Press, 1990.

Glendon, Mary Ann. Rights Talk - The Impoverishment of Political Discourse. New York, London et. al.: The Free Press, 1991.

Held, David. Democracy and the Global Order - From the Modern State to Cosmopolitan Governance. Stanford: Stanford University Press, 1995.

Kukhathas, C. e Pettit, P. Razols - 'Uma teoria da justiça' e seus críticos. Trad. M. Carvalho. Lisboa: Gradiva, 1995

LOCKE, John. A Letter Concerning Toleration. In The Great Books, Chicago: Encyclopaedia Britannica, 1952.

Carta acerca da intolerância. Trad. Anoar Aiex. In Os Pensadores. São Paulo: Abril Cultural, ${ }^{2} 1978$.

Mulhall, Stephen \& SWIFt, Adam (eds.). Liberals and Communitarians. Malden: Blackwell, ${ }^{2} 1997$.

NickEL, James W. Making Sense of Human Rights. Berkeley/Los Angeles/ London: University of California Press, 1987.

Popper, Karl, A logica da pesquisa cientifica. São Paulo: Cultrix, "'1996.

Rawl.s, John, A Theory of Justice. Cambridge: The Belknap Press of Harvard University Press, 1971.

Political Liberalism. New York: Columbia University Press, 1993, 1996, including "Reply to Habermas". 
RorTY, Richard. Contingência, ironia e solidariedade. Trad. Nuno Ferreira da Fonseca. Lisboa: Editorial Presença, 1992.

Rounnet, Luiz Paulo. À Paz Perpétua: Estudo sobre o pensamento político de Kant. Dissertação de Mestrado. São Paulo: FFLCH - USP, 1994.

- O enigma e o espelho - Uma análise dos discursos sobre a paz de Erasmo e Rawls. Tese de doutorado. São Paulo: USP, 2000.

Rousseau, Jean-Jacques. Esquisse sur le projet de paix perpétuelle de l'abbé de Saint Pierre. In Oeuores Complètes, t. III, Pléyade. Paris: Gallimard, 1964.

Saint-Pierre, Abbé de. Projet pour rendre la paix perpétuelle en Europe, presenté par Simone Goyard-Fabre. Paris: Garnier, 1981.

SEN, Amartya and Williams, B. (eds.). Utilitarianism and Beyond. Cambridge: Cambridge University Press, 1992

Torrel, Jean-Pierre. Iniciação a Santo Tomás de Aquino. Trad. Luiz Paulo Rouanet. São Paulo: Loyola, 1999.

Walzer, Michael. Das Obrigaçẽes Politicas. Trad. Helena Maria Camacho Martins Pereira. Rio de Janeiro: Zahar, 1977a.

. Just and Unjust Wars, New York: Basic Books, $1977 \mathrm{~b}$.

$S$ pheres of Justice. New York: Basic Books, 1983.

. The concept of civil society. In IDEm (ed.). Tozuard a Global Civil Society. Oxford: Berghahn Books, 1995.

$\overline{\text { Press, } 1997 .}$

On Toleration. New Haven and London: Yale University

Da tolerância. Trad. Almiro Pisetta. São Paulo: Martins Fontes, 1999

Endereco do Autor:

Rua Capote Valente, $462 / 121$

05409-001 São Paulo — SP 